\title{
Reflections on engaging the potentially "difficult" patient
}

This article was published in the following Dove Press journal:

Medicolegal and Bioethics

16 February 2015

Number of times this article has been viewed

\section{Edmund G Howe \\ 'School of Medicine, USUHS, ${ }^{2}$ Center for the Study of Traumatic Stress (CSTS), Bethesda, MD, USA}

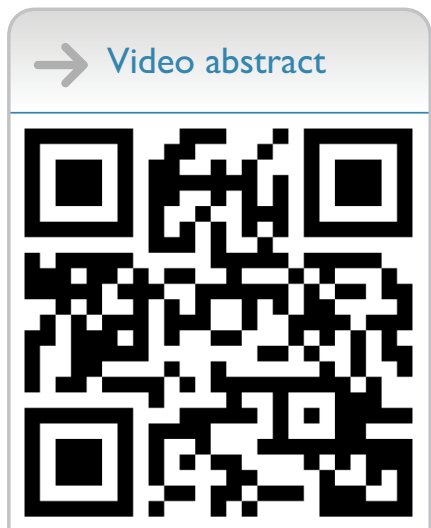

Point your SmartPhone at the code above. If you have a $Q R$ code reader the video abstract will appear. Or use: http://dvpr.es//zatoHn
Correspondence: Edmund G Howe

Tel +I 30I 2953097

Fax + I 30I 295 I536

Email edmund.howe@usuhs.edu
Abstract: Care providers encounter problems working with patients in many contexts. However, they often may have had a role in creating these problems, which may be within or outside their awareness. This piece presents several ways in which these problems may arise and provides guidance as to how clinicians may best prevent these problems from occurring and how they may best respond to the problems once they occur. It also addresses how care providers can best, at this same time, protect themselves under the constraints of the applicable laws.

Keywords: ethics, law, patient/doctor relationship, resistance, trust

\section{Introduction}

One of the greatest challenges clinicians face is treating "difficult" patients. Still, there are approaches care providers can take to overcome many of these challenges. Close attention to patient/staff interactions that have preceded these problems often, for example, reveals ways in which staff members, even if inadvertently, have precipitated them. In one study of 115 psychiatrists treating patients in outpatient settings, for example, of those who had been assaulted, 53\% thought they had played a role in provoking these attacks. ${ }^{2}$ This finding suggests optimism with regard to our doing better because it suggests a direction we can pursue to try to improve our present practices. That is, if clinicians can increase their skills in these areas, patients" "resistive" and "noncompliant" behaviors should decrease.

How care providers may best do this is the focus of this article. I discuss many ways in which clinicians may proceed optimally. All these approaches are intended, basically, to first establish and then maintain patients' trust. With this trust, clinicians can work with patients to try to achieve what, in these patients' views, are optimal outcomes, whether these outcomes are primarily therapeutic or palliative in nature.

Many of the interventions I suggest are currently uncommon, and some are counterintuitive. ${ }^{3}$ They may, however, go a long way practically.

I initially discuss core presuppositions about ethics that care providers should consider. This prereflection is critical. The contexts considered will be wide-ranging, from patients who want to leave the hospital against medical advice, to those who are comatose. This wide range is intended to illustrate the virtually limitless contexts in which the interventions I propose may be beneficial.

In these situations, clinicians may seek ethics consultation. Whether they or the ethics consultants intervene, the same psychological considerations may exist. Thus, the approaches I suggest may apply to both groups. 
I then discuss general and specific approaches care providers may take, dividing the specific approaches into three stages: What they should do initially, what they should do later, and what they should do to provide follow-up care.

My general thesis throughout this discussion is that the term difficult patient, as used in this article's title, is misleading, as it implies this difficulty comes wholly from patients when it may, as indicated earlier, be a result of interpersonal factors. ${ }^{4}$ Staff members may also contribute to these behaviors. Thus, these behaviors may more rightly be regarded as at least somewhat iatrogenic.

\section{Key perspectives and attitudes}

It is important that clinicians have sound views regarding what they can and cannot offer. Perhaps the most important of these perspectives is what ethics itself, as a discipline, has to offer, and what it does not, as this determines what the clinicians have to offer as well.

\section{The limits of ethics}

Because of their experience, clinicians often have profound knowledge as to how patients with similar conditions may emotionally react. Thus, in this way, as in numerous others, they may benefit patients greatly by bringing this knowledge to their attention. There may, however, then come a time at which clinicians could cross the line such that they might, wittingly or unwittingly, risk imposing their own ethical view. This is, of course, problematic, primarily because of the unequal power of the clinicians.

Even in theory, "ethics" often cannot provide a right answer. This is because ethics cannot always indicate, in a way that is rightly self-evident to all, which of several values that compete and are mutually exclusive should prevail. Ethics cannot indicate, unequivocally, for example, the right answer to such questions as whether assisted suicide should be permissible. Here the value conflict that may be beyond ethics resolving is whether the value of the sanctity of human life should prevail over the conflicting values of patients' autonomy, and particularly of patients having the autonomy to be able to choose to relieve their own suffering by dying.

Still, ethics in some contexts may be able to show what is right or wrong. An example might be leaving infants in substantial pain: This wrong may be more self-evident because we can easily imagine this pain. Thus, if there is no comparably strong conflicting value, such as the sanctity of this infant's life that not relieving this infant's pain would bring about, the argument for relieving the infant's pain would be more likely to self-evidently prevail.
A critical clinical implication of this limit within "ethics" is, then, that care providers may not have a better ethical view of what patients should do. Clinicians must keep in mind, therefore, that even though they may be leading experts in fields such as infectious diseases or cardiology, and even though they may have had many years of clinical experience, it does not follow that they have moral expertise that is greater than that of their patients.

The error clinicians make when they assume that they have greater ethical expertise than others due to their experience and/or medical training was discussed by Robert M Veatch, ${ }^{5}$ who stated that although people with scientific expertise may also have greater ethical expertise, this cannot be assumed. Rather, this expertise must be demonstrated.

\section{Practical implications Clinicians accepting they may lack greater moral expertise}

The core, practical ramification of the above considerations is unequivocal: Care providers should accept that, with regard to outcomes, they may not have superior moral expertise.

Having accepted this, they should then also know that patients are most likely to be fully capable of understanding all the concepts they need to be able to understand to make decisions regarding themselves, so long as, of course, they are legally competent. Here is no place for care providers to reason, "My patient can't possibly understand, because he or she is not a clinician."

A care provider, accordingly, might say, "This is what I think should be on the table, because in my experience, this is what patients have found most important to take into account in the past. I would be willing to share with you what in this instance I would do, but only if you want me to. There is simply no way in which I can say what I would or should do, however, if I were in your shoes. How I might put together all the factors you might want to consider may, at the same time, be helpful to you. I fear, however, that if I share my view with you, this may make it harder for you to then go a different way. We can decide what you want me to do, now, any time later, or not at all." This last phrase gives patients the greatest flexibility.

Care providers may reveal their bias inadvertently. This may occur outside their awareness and nonverbally. They may, for instance, raise an eyebrow in response to something the patient has said. For this reason, clinicians should keep a sharp eye out for any indication on the part of the patient that this has occurred. I shall discuss later what the clinician should do if this does occur. 
This risk is one reason some care providers advocate mediation as a preferable first step in trying to help patients, families, and/or staff resolve ethical conflicts. Mediators try to focus on maintaining moral neutrality. This, they believe, leaves patients and others freer to negotiate their differences.

Patients may, in contrast, much want care providers' recommendations, even if they do include their personal and even idiosyncratic ethical judgments. They may trust their clinician's capacity to integrate complex factors and/or may believe, possibly rightly, that their care providers are more objective, and thus more likely to be "on target," than they are. So long as clinicians have informed patients of the risk I have outlined here, it may be far optimal, then, for them to share their recommendations.

\section{Responding after discovering biases}

The analysis here raises the question of what, having discovered a bias, care providers should say. Patients have become enraged at ethics consultants who have had a bias, but have not shared it, when patients later discover the bias.

A consultant urged parents, for example, to maintain the life of their child, an infant, who had a dismal prognosis. Subsequently, this infant underwent what appeared to be a long, grueling death. He grimaced and cried, although it was unclear whether these responses were reflexive. The parents later found out that this care provider had a devout religious view favoring the absolute value of the sanctity of life under all circumstances. They felt that by all means the consultant should have told them this, because if he had, they then would have seen his views in a wholly different light.

Care providers sharing their views in all cases may, at the same time, bias some patients against them. This also may be more likely to occur among patients more predisposed to be "difficult." Care providers sharing a bias with which these patients particularly disagree may, then, unnecessarily precipitate a negative response.

One possible solution here is for care providers to spell out the relative pros and cons of their sharing their views before expressing them, and then to ask their patients about whether they would want them to share their views.

They might say, for example, "I have a bias, but my bias may be like my liking chocolate ice cream and you liking vanilla. It may merit no moral weight. I will try, as best I can, not to allow my bias to affect anything I do or say. If you want to know my bias, however, I would be happy to tell you. And if you at any time feel I might be responding to my own bias, please also let me know."

\section{Scanning for personal interest}

When care providers consult on ethical issues, their own interests also may affect their decisions, again possibly outside their conscious awareness. Here, for example, their interests in abiding by the law and not offending other interests may prevail. I provide here three examples and then suggest some general clinical guidelines for responding in these situations.

\section{Hoarding medications}

Often, care providers' main personal interests include adhering to their medical licensure requirements and to the rules of the institutions that employ them. Both may conflict with what the providers morally believe.

For example, a care provider was seeing a hospice patient as an outpatient. He learned from this patient that she was harboring medications in case she decided she wished to end her life earlier than it would otherwise, most likely, "naturally" end. This care provider believed that he had an obligation to report this patient. Because she possibly planned to prematurely end her life, she was at risk, he feared, of committing suicide.

Her fellow care providers thought otherwise. They believed this care provider should respect this patient's choice and that he should keep this information confidential, particularly because if she could continue to share her fears and feelings, this would decrease the risk of her deciding to prematurely end her life.

\section{Antisuicide contracts}

Another example, and one that is perhaps more controversial, involves mental health care providers asking suicidal patients to sign an antisuicide contract in which they agree to contact their doctor, call 911, or go to an emergency room if they feel acutely suicidal and are not sure they will not end their life. This has, for many, been common practice in the past. ${ }^{6}$ Recent studies have not found, however, that these contracts reduce the risk for patient suicides, ${ }^{7,8}$ and some now feel, even, that asking patients to sign contracts is contraindicated. Care providers may hope by these contracts to convey that together, they will help these patients be "safe"; regardless, their asking some patients to sign such contracts may decrease their trust. ${ }^{9}$

Years ago, for example, a care provider was required by his department chief to have all patients voicing suicidal thoughts sign an antisuicide contract. She felt this policy was wrong. She asked her patient to sign this contract but also told him she did not agree with this policy. The patient respected 
her for saying this and did not sign this contract; then, with her help, he did well. The provider did not get fired.

\section{Signing out against medical advice}

A final example posing this conflict between patient interests and what the law or an institutional policy requires involves care providers refusing to sign a patient out of the hospital AMA. Care providers not doing this may best protect the patient/care provider relationship by not risking conveying to the patient that the care provider is siding with the institution against him or her.

Again, this may leave the care provider at odds with his or her institution. This especially may be the case in this instance because the institution may see itself, rightly or wrongly, as being at an increased risk for civil suit or its members for even criminal prosecution. Still, care providers doing this may be ethically warranted in not signing the AMA document. By not doing this, they may not create a difficult patient.

\section{Clinical guidelines}

A first point here is that when care providers work with potentially difficult patients, they should strongly consider being "transparent" by sharing with patients why they are doing what they are doing. Indeed, this would apply to all patients.

A second point is that care providers should not deny to themselves their own emotional vulnerability. The pressures they face may trigger, for example, their own fear that their institution may take action against them, as suggested in the examples provided earlier. They may then react to this fear outside their awareness. They may, for instance, distance themselves or even act out their resentment of these patients for causing them to have this fear.

If, in addition, care providers do give patients their recommendations and these patients ignore them, care providers may then feel rejected. It is thus important that before offering recommendations, care providers remind themselves of what they should say to their patients: that they should still feel totally free to decide what they want.

What, then, might they do to best protect themselves legally in these instances? As a general rule, the law looks unkindly on care providers who give suboptimal care to a patient in an effort to protect themselves legally. Thus, legally, it is likely to be far preferable for care providers to do the best they can for their patients and then document why they have done this in these patients' charts.

In the example of the hospice patient hoarding medications, the care provider could explain, for instance, that he believed that by allowing this patient to know that she had this way "out," and by giving her the freedom to share this information, this would serve her best long-term interests. It is noteworthy that care providers have documented in much this same way why they have not involuntarily hospitalized chronically suicidal patients; namely, because in the long run, this too would go against their best long-term interests. This rationale has been accepted by courts.

It is always legally preferable, of course, in addition to providing documentation, for care providers to involve other staff members in making such judgments whenever they can.

With regard to care providers not asking patients to sign antisuicide contracts, care providers should consider beforehand informing appropriate people within their institution that they do not plan to do this and why. If they do not succeed in gaining their institution's permission, they can still tell these patients what they believe and that they have appealed but have not succeeded in gaining permission to deviate from this policy. This may "save" their relationships in spite of their not being able to accede to what such "potentially more difficult" patients would have wanted.

With regard to the care provider's not signing out a patient against medical advice (AMA), again, a care provider could choose to not sign out the patient AMA, to not be implicitly joining the hospital against the patient to protect the hospital legally. If, however, the care provider does this, he or she could then put a note in the chart clarifying his or her reason for not signing the patient out AMA. This might be, for example, that the care provider sees the patient's leaving the hospital as a reasonable personal decision on his or her part though not in his or her best medical interest. Alternatively, again, the care provider could at least inform the patient why he or she had to follow policy, even though he or she disagreed.

Ideally, of course, preventing patients from wanting to leave the hospital would be optimal. Care providers may further this outcome by being empathic when patients have substance abuse problems, by recognizing and addressing signs of patient distress early on, by seeing decisions from the perspective of the patient, and by ensuring patients fully understand their health risks. ${ }^{10}$

If patients still insist on signing out AMA, then clinicians also should arrange for adequate follow-up care. Otherwise, they could risk legally abandoning these patients. Abandonment also may exist if the care provider ends the patient/physician relationship at a time that is "unreasonable" or that is too brief to allow the patient to find a sufficiently qualified replacement. The ethical high road, here, is for clinicians, in addition to giving patients adequate time, to help the patient find a replacement. ${ }^{11}$ 
If, in contrast, it is medically necessary to continue to hospitalize these patients involuntarily, clinicians should again document their reasoning to avoid the risk of their being legally liable for false imprisonment. ${ }^{12}$

\section{Intervening}

There are some practices care providers should keep in mind and pursue at all times. There are others most indicated during different phases of patients' care. I discuss each of these in this order here.

\section{Core practices that are always applicable}

Two practices care providers should consider taking at all times are repairing and validating. Care providers constantly should look for any indication that a patient feels offended. If the care provider sees this, he or she should immediately repair the situation. Likewise, when a patient expresses a belief that the care provider thinks may be uncommon or controversial and, thus, may result in other care providers later confronting the patient, care providers should validate some part of the patient's view to establish with him or her an initial, therapeutic alliance. They should also inform them that this later confrontation may occur and explain why. ${ }^{13}$

\section{Repairing}

Staff members may inadvertently trigger patients' oppositional behavior in ways that are not foreseeable. Negative effects of care providers' interventions may occur no matter how expert staff may be.

An example is a doctor inquiring into previous psychiatric illness in a patient's family. A patient recited a long list of relatives who had mental disorders. This physician then said, "Wow!"

The patient took this, she later told me, as meaning to her, "Wow! Your family is really messed up!"

Patients may infer that clinicians have made this same kind of pejorative judgment from a clinician's raising a skeptical eyebrow in response to something the patient has said. The effect of this raised eyebrow may be even stronger than how a care provider responds verbally. For instance, one patient told her care provider that she had had a one-night stand the night before. He exclaimed, "You what?" She never returned to see him again.

Some patients have told me that they watch care providers' every nonverbal expression. If they perceive even a single instance of what they believe is or even just may be a care provider's negatively judging them, this is enough to dispel their trust.
This, of course, presents no small challenge to care providers. The harsh reality is that care providers cannot always avoid committing these offenses, and when they do, what they have done may remain hidden to them. Thus, they should always look for signs that this may have occurred. Hopefully, they will observe that they have offended patients as soon as this occurs. ${ }^{14}$

Once clinicians detect what they think may be such a negative reaction, they should inquire at once. They should do this immediately, regardless of whatever else they are doing at this time. They might say, for example, "It seemed for a moment that you felt uncomfortable about something. If you did, this could be in response to something I did or said. Did you feel uncomfortable about something?"

Signs of the patient's experiencing distress may, of course, come from other sources. The patient may suddenly, for instance, have an association, based on what he or she has experienced before. This painful past experience may have been retriggered.

If patients then share that they are upset and that this is because of what the care provider has done or said, the care provider should immediately "repair." This repairing should not be at all equivocal: The care provider should not at all hedge, such as by implying that he or she is only somewhat at fault, even if he or she thinks that this is the case.

He or she should not say, for example, "I'm sorry you got upset." This would leave open to the patient the possible inference that the doctor thinks he or she is not really at fault but that the patient is just oversensitive. The clinician should say, rather, "I'm terribly sorry I upset you."

This, of course, is another example of how just one "wrong" word, as one "wrong” tone, may evoke patients' distrust.

\section{Validating patients}

It is also essential, as early on as possible, for care providers to validate patients' perspectives when it seems plausible that their views may later be questioned. This validation is always possible because there is always something sound within what patients say.

As an example, care providers might validate whenever a patient expresses anger: People do not feel angry for no reason.

Care providers may also go beyond this. They may also comment on a patient's implicit strength, which they can infer underlies what the patient has said or done.

They might express here, for instance, using this same example, how much they appreciate the patient's capacity to both recognize and express what he or she feels. The clinician could say, for example, "I'm so glad you told this to me and 
that you were able to see that you felt this way and to tell me. I need you to do this to see what I miss. Thank you. Please always tell me everything like this, just as you did now."

This is, of course, true. If patients do not indicate their anger, they may express it in destructive ways. They may, for instance, be wholly compliant for a while, only to, consciously or unconsciously, act out their anger later by then being noncompliant. They may, as other examples, not do what their care provider has advised them and not tell him or her that they have not done so, or they may not return.

\section{Core considerations at specific times}

There are some interventions care providers should keep in mind, especially at different times.

\section{Preparing before seeing the patient}

Care providers may have perspectives and attitudes before seeing some patients that will thwart their capacity to be most effective if they leave them unchanged. Thus, if they receive information about a patient before seeing him or her and have negative feelings, they should attend to these feelings before the first meeting between them and this patient.

\section{Hidden agendas}

Care providers should review specifically, for example, whether they have, knowingly or unknowingly, some hidden agenda. If they do, this may work insidiously against them. Those clinicians who have consulted them and asked them to intervene may, for example, have wanted them to pursue needs they have, such as to insist on these patients not having further treatment they view as futile.

When others ask care providers to consult, they may hope that others, such as ethical consultants, can convince these patients to do what they want them to do. An example is patients who require ongoing blood transfusions. A hospital blood bank may become concerned that there might not be enough blood for others who also need it and, thus, apply a utilitarian ethic and display their concern for "the greatest good for the greatest number." The blood bank may then ask the ethics consultant to consult but in reality want him or her to convince the patient to accept giving up further transfusions, although the result of this may be or will be the patient's death.

Here, it may seem optimal to try to reframe the blood bank's request in a way that most helps the patient see how others' needs conflict with his or her needs. One might, then, ask the patient how he or she thinks this dilemma might be best resolved. ${ }^{15,16}$

This may, however, only alienate the patient. The patient may see this intervention as an attempt to convince him or her to not receive any more blood and to die. These patients might, then, also see this care provider as deceitful.

The ethics consultant's best option in this instance may be to decline doing the consult altogether. This may be the only way in which he or she can maintain integrity when consulting with the patient. He or she could also be honest about his or her role and say that he or she is indeed there to try to persuade the patient to give up continuing to receive blood, knowing that this may result in the patient's death.

This example is noteworthy in that it illustrates particularly well how it may be that care providers inadvertently may see a patient as difficult when the patient's response is in part a result of their words and actions. That is, the ethics consultant may be acting to persuade, but saying otherwise. This may rightly appear to the patient as the care provider's attempting to con him or her. If patients respond negatively to being conned in this context, especially as this involves their life or death, this is appropriate.

\section{What patients should know}

A second key item care providers should also consider before meeting with patients is what information they should ensure patients know. In many contexts, of course, this information may be critical to patients' decisions, as only with this information may they be able to decide what they most want.

An optimally paradigmatic example here is care providers informing patients in advance of how the law works and of the conditions under which the law may apply.

An example involves a patient in a coma and his family. The patient was dying because of incurable cancer. He was unconscious and in a coma as a result of an infection. This infection was caused by an abscess that surgically could be treated. If successful, it was expected that he would come out of his coma and then live, perhaps, 6 months longer.

Should he have this surgery? His wife thought he would not want this intervention. He would not want to, she believed, again become alert and then live on only for 6 months or so, "just to die." His parents and adult siblings all thought he would want to live on.

The applicable law, in this instance, was that the wife should decide on his behalf. This would then mean that the family's subsequent task would be to accept this and forgive her.

Another course they could consider, however, was to discuss this together and arrive at a compromise view with which they could all agree. This would represent what, having put their minds together, was their best guess regarding what this patient would want.

With this information about how the law worked, they made this choice together. It turned out that the antibiot- 
ics "worked," precluding the need for this surgery. Once awake, this patient said that he would not have wanted this surgery, as his wife had said. He died, as expected, in about 6 months.

He might, of course, have said that he would want what all would agree to if he had been asked this before he went into the coma. Care providers anticipating this possibility, then, might ask this. They could also, in analogous situations, take this possibility into account even after patients can no longer speak. They can debate and perhaps conclude that a patient would have wanted this.

There is no legal prohibition to care providers sharing with patients different options they have within the law. Care providers should tell patients whatever they believe would be relevant to themselves if they were making the same decision. This approach has the additional advantage of equipping the patient and/or family with more comparable expertise, enabling them to work together more as equals.

\section{Intervening at the bedside}

There are several concrete interventions care providers should consider at "the bedside." I discuss these in three main stages: when they meet the patients, as they proceed, and before they leave.

\section{Initial impression}

Once together, care providers should pay attention to where they sit. ${ }^{17}$ It is best to not sit directly opposite patients, as this may create an unconscious sense that they are opposing or confronting them.

They might, ideally, in addition to this, try to find a way to sit so that their and their patients' eyes can be at the same level. Care providers should, at least, not sit in chairs exceptionally higher than their patients if they can avoid this. They may also, if exceptionally tall, slouch, but this poses another risk, as patients may see this as smugness. Care providers can also indicate in advance how much time they expect they will, in all, have with their patient. They may add that they are sorry that they cannot have more time and indicate what they will do if there is more to discuss when the time is expired.

These interventions may best set the tone for future interactions and, thus, make them more likely to succeed. This should also make it less likely that the care providers will provoke more difficult patients.

These initial steps are particularly important when care providers' agendas may affect the ends of patients' lives. Families may see ethics consultants, for example, as being there to discuss with them not whether, but how, their loved ones will die.
This problem may arise, for example, when a person comes in to see a patient and has a name tape saying "hospice." This may signal to a patient or family that this care provider is there because the patient may or will soon die. This also occurs when a care provider comes from a palliative care service. Patients and families may infer, rightly or wrongly, that a loved one is likely to die in the near future.

Care providers knowing this can help counter this initial response by asking patients early on what their coming in to talk with them means to them. Care providers can clarify, for example, that their coming to see the patient does not mean they they are coming because the patient is about to die. To the contrary, care providers with expertise in palliative medicine now are urged to come in as early as possible in the course of a patient's illness in order that they can provide whatever they can. Palliative measures may, then, be given at the same time as efforts to cure or reverse an illness. If the patient is dying, their care provider should present this news to them at an earlier time.

Care providers consulting because patients may or will die may then inform the patients of the possible gains they can offer. They may, for example, offer them additional alternatives.

Care providers can brainstorm with patients, for example, after they say what they want, ways in which the providers can potentially help bring the desired situation about. They may also tell patients' families in advance, for instance, that the legal rule is that they must say not what they want but what they believe the patient would want. Knowing this in advance, the family could say what they want but report it as if they believe this would be the desire of their loved one, the patient. Here, they serve the family by giving them accurate information they might want to have. In this case, this might enable them to do what they believe in and want at the "price" of this violating the law's intent. This price may be both warranted and unavoidable.

Care providers may also serve more directly as their patients' advocates.

Care providers must not, here, wear two hats when they suspect something may be going on within a patient's family that is underhanded. An example is a family's seemingly seeking gain by continuing to get a patient's welfare checks, which they can do only by keeping him or her alive.

Care providers should recognize and consider in these contexts that they may simply not be able to serve two masters adequately at the same time: They may not be able to both meet these patients' families' need to trust them and, simultaneously, surreptitiously, investigate them as well. 
If care providers to any degree do the latter, patients and families may rightly regard them as betraying them. Care providers are likely to reveal this double agency in their nonverbal behavior. Care providers choosing to avoid this double agency may, then, not be as able to detect fraud. They should see this loss and accept it as an unavoidable price, which may make it easier to bear.

Care providers, finally, as early as possible during their initial interview, should ask the patient about what, at that moment, he or she is most concerned. This may be not the patient's illness, nor even their concern that they may die. This may be, "If I must come into the hospital, who will take care of my cat?"

By the care provider's asking this, the patient, at the very least, will most likely recognize and appreciate that the care provider, in doing this, has put his or her own agenda aside. The patient may then believe that instead of his or her care provider's seeking only to come up with the right diagnosis, or what needs to go into his or her chart, this care provider is more truly concerned about what is going on within the patient.

\section{Proceeding}

Care providers' anticipating and then responding to patients' foremost needs is an attitude the providers should always assume throughout their interactions with patients.

Another example of this occurs when a patient needs a biopsy to determine whether the patient has cancer.

Such a care provider can greatly benefit such a patient by providing greater emotional relief, such as by saying, "When I get back the biopsy results, I shall call you immediately." This can go an extremely long way in gaining and cementing patients' trust. Further, if the care provider is the same one who would do the biopsy, he or she may be able to further gain trust by fitting the patient in then and there.

The patient may, then, go for just days, rather than longer, before learning the diagnosis. If the result is incurable cancer, this may not make so much difference, but if the biopsy is benign, this may save the patient much prolonged fear. In addition, this will help bond the patient's and care provider's relationship.

A final, common question here is how much information in a situation like this the care provider should give to the patient before the patient receives the results of the biopsy. Some patients, once told of the possibility of having incurable cancer, want to know all the information possible. This includes their worst-case scenario. If, for example, their worst-case scenario is prostate cancer, they may ask, "Will I be impotent?"

Care providers may be tempted in these situations to simply provide all the information these patients want, which most respects the patient's autonomy. Yet this may be suboptimal, as after receiving this worst case information, some patients may be haunted by it from that point on.

Care providers knowing this may then ask these patients whether they would like to discuss with them the pros and cons of knowing all this information before deciding whether they want it.

There is, in fact, no down side to asking patients what they would want in any context whenever there are grounds for any doubt.

\section{Last steps}

Care providers should take the initiative to ask patients, before ending their time with them, whether they have any questions. This is common knowledge. They should, however, then pause and ask again, which is not common knowledge. This method is recommended because even when patients are usually most assertive, they may fail to ask all the questions they have unless strongly encouraged to do so. This may be because they know most care providers have highly limited available time. They may, in light of this, on a deeper level, also fear offending their care provider and/or possibly also receive worse care as a result.

Care providers should, likewise, also always ensure patients have a ready way to inquire, whether and when future questions arise. Ideally, this should be someone, somewhere available 24 hours a day. If the patient can only leave a message, they should know when they can expect either the care provider or another clinician to get back to them. This is critical, as they may sit by the telephone, waiting for this call.

Care providers might also inform patients about the extent to which they will "fill in" those whom patients may call about specifics regarding the patient's condition. This way the care provider filling in will know about the patient if and when he or she calls and will be better able to respond to the patient's idiosyncratic medical needs. As a general rule, care providers should always explain why they cannot do something in a patient's best interest. An example is the patient who asked for an earliest possible appointment, but in any case, an appointment at some time before she had plans to go away on a vacation. Her care provider simply said, "No. This isn't possible." This “difficult" patient felt enraged not because of what this doctor said, but because she felt he had dismissed 
her as if she deserved no indication of why the appointment scheduling was not possible. If he had just given her some idea why, she said, she would not have had had "any problem." In fact, he, too, was going to be away, and he was leaving the very next day. The patient may have seemed, again, to be "difficult" for feeling this way, yet the provider so easily might have avoided triggering her anger.

A care provider may believe that a patient with a problem with alcohol should get him or herself on his or her own to an Alcoholics Anonymous (AA) meeting. This would be a mistake. If the patient will go only if the care provider or someone will pick the patient up and go with him or her, efforts should be made to do this. Otherwise the patient will not go to AA and the chance that this will help will be reduced. ${ }^{18}$

A paradigmatic example here is the person with a problem with alcohol who will not go to an AA meeting on his or her own. The solution may be to find a way for someone to take him or her.

\section{Conclusion}

Patients may be difficult, but care providers can interact suboptimally as well. Care providers may cause patients to be "difficult" by offensive and insensitive behaviors on their part. They may have no idea though that they have been offensive. They may blame the patient as opposed to seeing themselves as the problem. This piece has highlighted ways in which care providers may actually be the source of these problems, though they themselves may not be aware of this.

Chief points about which care providers should be always aware are the need to do whatever is necessary to try to heal or repair any damage to the relationship and subsequent trust after a care provider has upset a patient. This may mean, for example, inquiring as to whether the patient is upset at something he or she did and the care provider's saying he or she is sorry. when patients seem upset and to validate some part of patients' thinking when they express wants likely to later be problematic.

Once at their bedside, the providers should prepare how they will view the patients they see, attend to how they sit, and, by all means, ask patients early on what is most important at that very moment to them.

Later, they should do all they can to meet their needs, and if they cannot, explain why.

When they leave, they should ensure patients have contact information so that the patients can feel certain they have rapid access to information and advice regarding concerns that arise later.
Most important is how care providers regard the law. Rarely, if ever, is a care provider punished for doing what he or she thinks is best for a patient. Even if care providers violate the law for this reason, they may not be convicted or even indicted if they did what they thought was best for the patient. The law purposefully wants care providers, when in doubt, to do what they believe is best for their patients, not what they believe would most legally protect themselves. A recent example illustrating this priority involved care providers' responses in a hospital after Hurricane Katrina. They may or may not have sought to spare some patients from suffering by precipitating their death. This is not known. Even in this instance, however, although homicide was at issue, they were not indicted. ${ }^{19}$

Care providers' best efforts for their patients are, then, virtually always warranted, and these efforts can, in general, minimize the likelihood of precipitating difficult responses from patients who are so predisposed.

There will be, however, unavoidable incidents that care providers simply cannot prevent because of the inherent ambiguities in both what they say and what they do and as a result of the different ways patients respond. ${ }^{20}$ Care providers, accordingly, should accept that there are some patient difficulties they most likely will never be able to avoid and that, at the same time, the difficult behaviors patients show may, paradoxically, at least in small part, be a result of the providers' words and actions. Even here, though, care providers may anticipate words they may say that may have ambiguous meanings and thus be misinterpreted by patients.

Foreseeing this possibility, care providers may avoid this, by noting this ambiguity beforehand and clarifying in advance which meaning they intend.

\section{Disclosure}

The opinions or assertions contained herein are the private ones of the author/speaker and are not to be construed as official or reflecting the views of the Department of Defense or the Uniformed Services University of the Health Sciences. The author reports no conflicts of interest in this work.

\section{References}

1. Yudofsky S. Fatal Flaws/Navigating Destructive Relationships with People with Disorders of Personality and Character. Washington, DC: American Psychiatric Publishing, Inc.; 2005.

2. Madden DJ, Lion JR, Penna MW. Assaults on psychiatrists by patients. Am J Psychiatry. 1976;133(4):422-425.

3. Howe EG. Reaching the unreachable; lessons from 5 influential therapists. Psychiatry (Edgemont). 2004;1(1):20-26.

4. Mitchell CW. Effective Techniques for Dealing with Highly Resistant Clients. 2nd ed. Johnson City, TN: Clifton W Mitchell Publishing; 2007. 
5. Veatch RM. Generalization of expertise. Stud Hastings Cent. 1973;1(2): $29-40$.

6. Miller MC, Jacobs DG, Gutheil TG. Talisman or taboo: the controversy of the suicide-prevention contract. Harv Rev Psychiatry. 1998;6(2): 78-87.

7. Edwards SJ, Sachmann MD. No-suicide contracts, no-suicide agreements, and no-suicide assurances: a study of their nature, utilization, perceived effectiveness, and potential to cause harm. Crisis. 2010;31(6):290-302.

8. Edwards S, Harries M. No-suicide contracts and no-suicide agreements: a controversial life. Australas Psychiatry. 2007;15(6):484-489.

9. Ganzini L, Denneson LM, Press N, et al. Trust is the basis for effective suicide risk screening and assessment in veterans. J Gen Intern Med. 2013;28(9):1215-1221.

10. Alfandre DJ. "I'm going home": discharges against medical advice. Mayo Clin Proc. 2009;84(3):255-260.

11. Blake V. When is a patient-physician relationship established? Virtual Mentor. 2012;14(5):403-406.

12. Reeves RR, Pinkofsky HB, Stevens L. Medicolegal errors in the ED related to the involuntary confinement of psychiatric patients. Am J Emerg Med. 1998;16(7):631-633.
13. Otani A. Resistance management techniques of Milton H Erickson, MD: an application to nonhypnotic mental health counseling. J Ment Health Couns. 1989;11(4):325-334.

14. Forrest DV. FRONTLINE: teaching affect recognition to medical students: evaluation and reflections. J Am Acad Psychoanal Dyn Psychiatry. 2011;39(2):229-241.

15. Resnicow K, McMaster F, Rollnick S. Action reflections: a clientcentered technique to bridge the WHY-HOW transition in Motivational Interviewing. Behav Cogn Psychother. 2012;40(4):474-480.

16. Westra HA, Aviram A. Core skills in motivational interviewing. Psychotherapy (Chic). 2013;50(3):273-278.

17. Gabbard GO. Psychodynamic Psychiatry in Clinical Practice. 5th ed. Washington, DC: American Psychiatric Publishing; 2014.

18. Aviram A, Westra HA. The impact of motivational interviewing on resistance in cognitive behavioural therapy for generalized anxiety disorder. Psychother Res. 2011;21(6):698-708.

19. Fink S. Five Days at Memorial/Life and Death in a Storm-Ravaged Hospital. New York: Crown Publishers; 2013.

20. Shapiro RJ. Resistance revisited: the therapist as surrogate family. Am J Psychother. 1972;26(1):112-122.
Medicolegal and Bioethics

\section{Publish your work in this journal}

Medicolegal and Bioethics is an international, peer-reviewed, open access journal exploring the application of law to medical and drug research and practice and the related ethical and moral considerations. The journal is characterized by the rapid reporting of reviews, case reports, guidelines and consensus statements, original research

\section{Dovepress}

and surveys. The manuscript management system is completely online and includes a very quick and fair peer-review system. Visit http://www.dovepress.com/testimonials.php to read real quotes from published authors. 